\title{
Lampu Emergency
}

Titi Kamal ${ }^{1}$, Hadi Bambang Setiawan ${ }^{2}$

${ }^{1}$ D3 Teknik Komputer, Politeknik Negeri Samarinda, 75321, Indonesia Provinsi Kalimatan Timur Kota Bontang

${ }^{2}$ D3 Teknik Komputer, Politeknik Negeri Samarinda, 92985, Indonesia Provinsi Sulawesi Selatan Kota Malili

Email : ZoeLev130613@gmail.com, Hadybambang6989@gmail.com

\begin{abstract}
Abstrak
Lampu emergeny memiliki fungsi utama yaitu sebagai penerang saat pemadaman listrik sehingga dapat membantu aktivitas manusia dalam melakukan berbagai pekerjaan khususnya di malam hari, alat ini merupakan salah satu alternatif yang aman digunakan dan alat-alat untuk membuatnya sangat mudah ditemukan di toko-toko elektronik. Lampu emergency salah satu inovasi baru dalam mengelola model serta mengkreasikan menjadi model yang lebih simpel dan tidak membahayakan pengguna dalam pemakaian. Dari segi harga pun, lampu emergency termasuk harga terjangkau bagi kalangan masyarakat dari ekonomi bawah sampai menengah, bukan itu saja lampu emergency bisa menjadi pilihan terbaik karena dari segi model, ketahanan, harga jauh lebih unggul dibandingkan alat penerang tradisional yang masih digunakan dikalangan masyarakat.
\end{abstract}

Kata Kunci : Lampu emergency, alat penerang, alternatif, pemadaman listrik

\section{Pendahuluan}

Lampu merupakan alat penerangan yang sangat penting bagi kebutuhan masyarakat. Namun, kondisi kelistrikan yang disuplai oleh PLN tidak sepenuhnya dialirkan secara berkelanjutan. Ada banyak faktor yang mempengaruhi terjadinya gangguan, misalnya kabel listrik PLN tertimpa pohon pada saat terjadi cuaca buruk membuat pemadaman listik terjadi sewaktu waktu. Hal tersebut membuat masyarakat terhambat melakukan aktivitas pada malam hari dalam aspek penerangan. Dalam hal ini, masyarakat desa lebih memilih menggunakan penerangan berupa 
lilin yang dianggap lebih murah, akan tetapi bahaya yang ditimbulkan dari lilin sangat besar salah satunya adalah kebakaran . [1]

Dari permasalahan tersebut, Lampu sederhana yang mana penelitian ini bertujuan untuk membantu warga masyarakat dalam aspek penerangan ketika terjadi pemadaman listrik dan meminimalisir terjadinya bahaya kebakaran. Maka dari itu kami membuat Lampu emergency yang bisa menyala di saat listrik padam. Lampu ini dilengkapi dengan baterai yang dapat diisi sehingga ketika lampu padam, maka daya yang ada di dalam baterai tersebut akan mengambil alih kebutuhan daya untuk lampu yang membuat lampu dapat tetap menyala ketika dalam kondisi listrik padam. .

Lampu emergency ini sangat bermanfaat ketika digunakan dalam kondisi darurat seperti saat terjadinya pemadaman listrik maupun evakuasi. Selain itu, lampu ini bisa digunakan untuk membantu kegiatan di lapangan atau outdoor, karena bentuknya yang praktis dan mudah di bawa kemana-mana

\section{Perancangan Lampu emergency}

Lampu emergency digunakan sebagai alat penerang untuk menggantikan fungsi alat penerang tradisional yang masih banyak digunakan di kalangan masyarakat. Kompenan yang dipakai saat merancang lampu emergency pun terbilang sederhana karena bisa ditemukan di toko-toko elektronik. Komponen yang dibutuhkan untuk membuat lampu emergency yaitu :

\section{A. Modul Joule thief}

Joule Thief atau dikenal pencuri energi adalah rangkaian yang bisa mengubah tegangan dari arus DC atau ke arus AC yang dapat menyalakan lampu dengan input bertengan rendah.

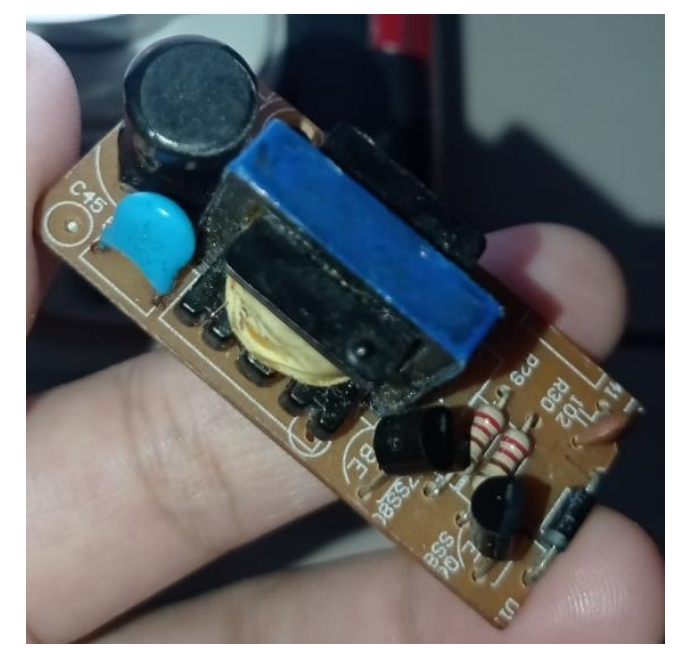

Gambar 2.1 Modul Joule Thief 
Terdiri dari beberapa komponen elektronik yaitu :

1. Trafo 7 kaki yang berfungsi mengubah arus AC menjadi DC ataupun menaikkan atau menurunkan tegangan listrik antar rangkaian.

2. 2 buah resistor dengan 1 nilai resistor adalah $220 \mathrm{ohm}$ dengan toleransi $5 \%$ yang berfungsi sebagai .pengatur dalam membatasi jumlah arus yang mengalir dalam suatu rangkaian.

3. 2 buah transistor $\mathbf{S} 8050$ merupakan transistor bipolar yang berguna untung menopang beban dibawah 700mA dan berfungsi sebagai penguat,penyearah, pengendali, mixer dan osilator.

4. Kapasitor $2221 \mathrm{kv}$ yang digunakan untuk menyimpan energi listrik sementara dan untuk menghindari dari loncatan bunga api listrik pada rangkaian.[2]

5. Kapasitor keramik 102 yang digunakan untuk menyimpan energi sementara.

6. Induktor berfungsi untuk memblokir arus searah (AC) ke arus bolak balik (DC).

7. Pcb joule thief yang digunakan untuk menghubungkan satu komponen dengan komponen lain.

B. Lampu LED 5 watt yang digunakan sebagai penerang.

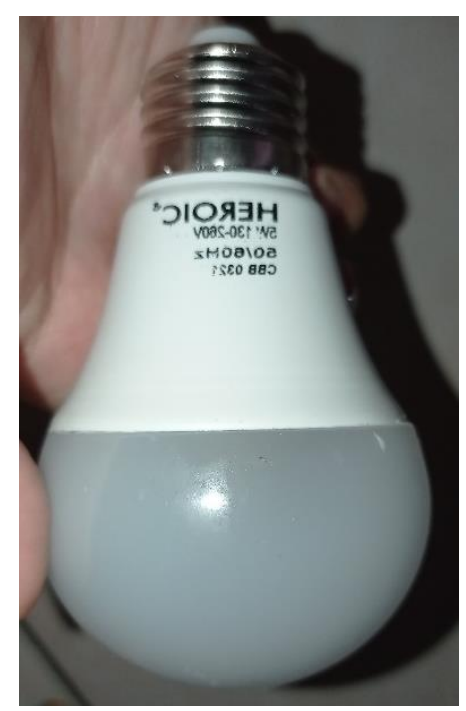

Gambar 2.2 Lampu LED 5 watt

C. Baterai Lithium-Ion 18650 dengan tegangan listrik 3,7 volt yang bisa di cas ulang (rechargeable) yang digunakan untuk menyimpan daya dan Holder baterai digunakan untuk menaruh baterai.[3] 


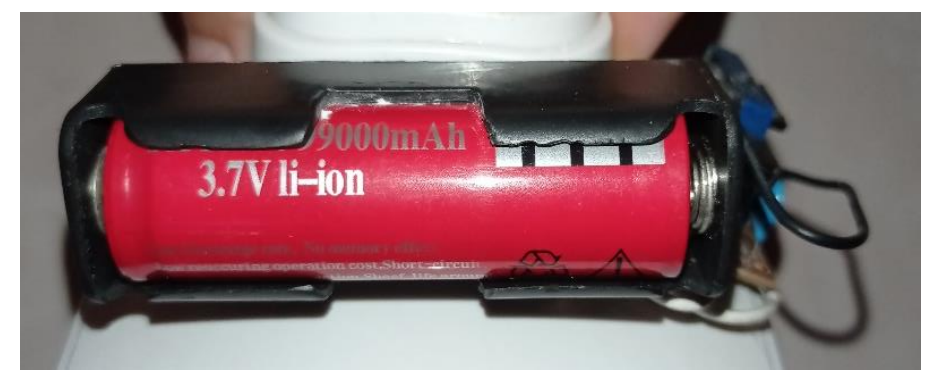

Gambar 2.3 Baterai Lithium-Ion 18650

D. Switvh On/Off digunakan untuk menyalakan dan mematikan suatu alat listrik.

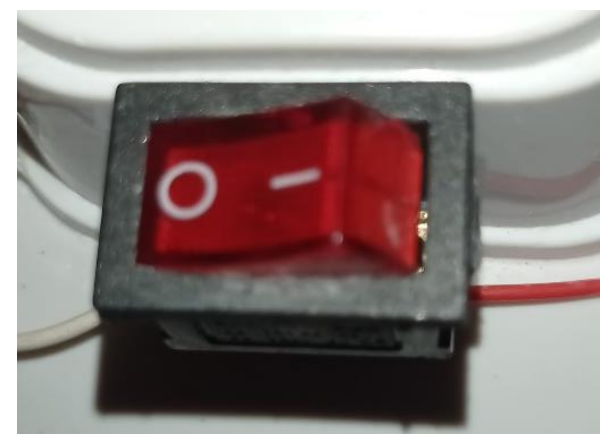

Gambar 2.4 Switvh On/Off

E. Fiting lampu yang digunakan menaruh lampu LED

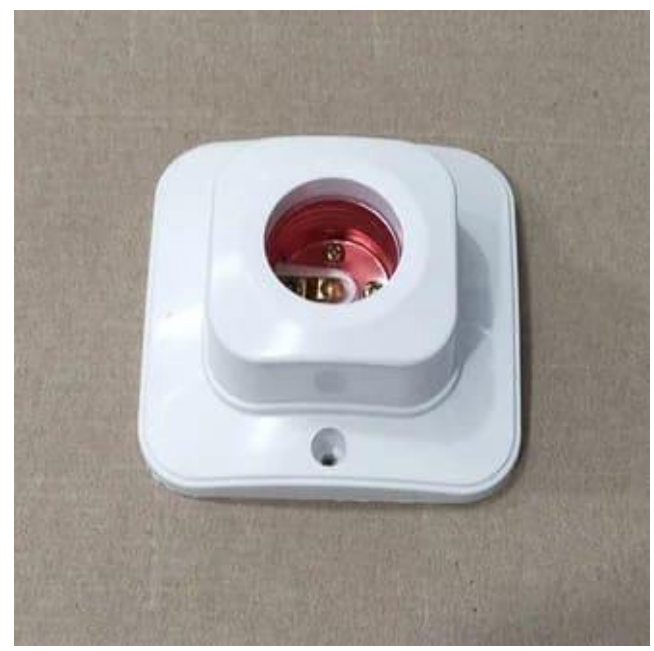

Gambar 2.5 Fitting Lampu

\section{Cara kerja}

Komponen utama untuk membuat lampu emergency yaitu menggunakan modul joule thief yang digunakan untuk menyalakan peralatan elektronik yang membutuhkan arus rendah seperti lampu LED dengan input baterai DC 3 volt atau baterai 3,7 volt yang outputnya bisa menyalakan lampu LED AC 220 volt. Komponen utama dari joule thief ini adalah transistor 
dan induktor, transistor dan induktor bekerja sama akan menghasilkan osilasi. Fungsi utama transistor adalah sebagai penguat sinyal dan switch (saklar). Pada rangkaian Joule Thief, transistor berfungsi sebagai pengontrol arus listrik. Dalam aplikasinya pada rangkaian elektronik, banyak digunakan sebagai penguatan pada sinyal listrik dan switch digunakan.[4]

Pada saat baterai memberikan tegangan pada rangkaian joule thief maka tugas-tugas komponen elektronik seperti resistor berperan sebagai regulasi arus yang akan membatasi dan menstabilkan tegangan basis. Trafo yang digunakan terdiri dari tiga lilitan, satu lilitan primer dan dua lilitan sekunder. Lilitan primer ini yang nantinya sebagai output rangkaian joule thief ini (dihubungkan ke LED 220V). Lilitan sekunder masing-masing 12 lilit, keduanya dihubungkan secara seri, pada hubungan keduanya disambung dengan lilitan induktor yang ke sumber tegangan baterai. Ujung satu diantaranya akan dihubungkan ke basis transistor melalui resistor dan ujung yang lain terhubung ke colektor transistor. Emitor transistor dihubungkan langsung ke sumber tegangan negatif baterai [5], switch on/off pada tegangan positif dihubungkan ke sumber tegangan positif baterai, dan switch on/off pada tegangan negatif dihubungkan ke sumber kapasitor keramik pada rangkaian joule thief. Setelah semua komponen terhubung dengan posisinya masing-masing maka ketika menekan switch on maka lampu akan menyala. Pada gambar 2.6 terlihat penyusunan komponen yang ditempellkan pada fitting lampu menggunakan lem.

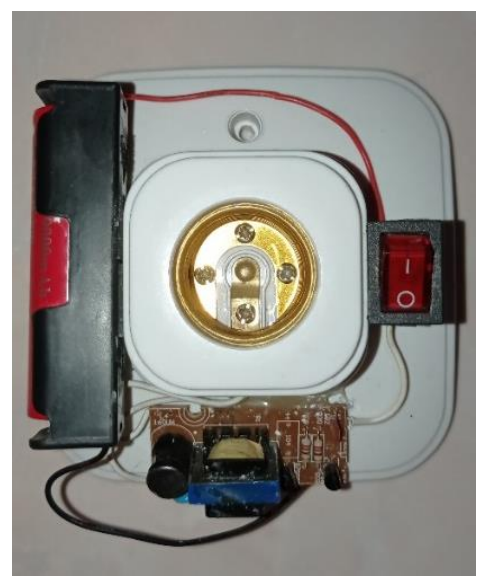

Gambar 2.6 penyusunan komponen lampu emergency 


\section{Hasil}

Hasil yang didapat saat mengerjakan lampu emergency yaitu mengetahui sebuah rangkaian sederhana yang bisa menyalakan peralatan elektronik yang membutuhkan arus rendah seperti lampu LED dengan baterai Lithium-Ion 18650 dengan tegangan listrik 3,7 volt yang outputnya bisa menyalakan lampu LED AC 220 volt 5 watt. Gambar 3.1 adalah hasil selama pengerjaan project lampu emergency. Ketahanan lampu bisa digunakan kurang lebih 5 jam pemakaian dan sangat aman untuk digunakan saat adanya pemadaman listrik.

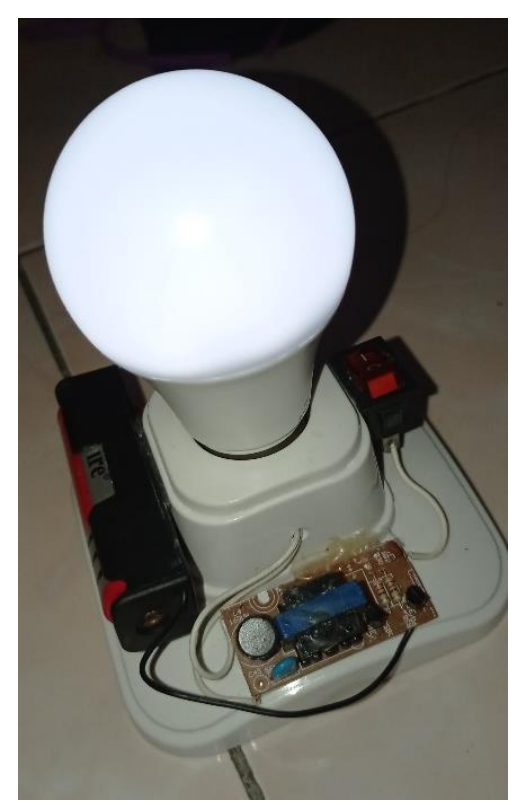

Gambar 3.1 hasil project yang dikerjakan

\section{Kesimpulan}

Lampu emergency yang berfungsi untuk menyalakan lampu disaat terjadi pemadaman listrik dengan menggunakan sumber tegangan dari baterai yang telah dirancang dan bekerja dengan baik. Sistem lampu emergency ini juga dapat digunakan sebagai sumber arus listrik dimana arus DC diubah menjadi AC dengan menggunakan rangkaian joule thief. Peralatan elektronik lainnya dapat dihubungkan dengan arus AC melalui saklar yang menjadi bagian dari perangkat lampu emergency. Perangkat lampu emergency ini menggunakan lampu komersial sehingga dapat diganti secara mudah sesuai kebutuhan.

Lampu emergency yang mengguanak rangkaian joule thief ini dengan 1 buah Baterai LithiumIon 18650 dengan tegangan 3,7 volt bisa menyalakan 1 buah lampu LED 5 watt selama kurang lebih 5 jam. 


\section{Daftar Pustaka}

[1] "Rekomendasi 10 Lampu Emergency Bagus dan Hemat Energi," [Online]. Available: https://cekresi.com/plus/article/rekomendasi-10-lampu-emergency-bagus-dan-hematenergi\#: :text=Lampu emergency ini sangat bermanfaat,mudah di bawa kemana-mana.

[2] S. Suratno, "ANALISIS PENENTUAN DAYA KVAR UNTUK MENGHINDARI PINALTY PT.PLN (Persero) PADA SAMARINDA CENTRAL PLAZA,” Just TI (Jurnal Sains Terap. Teknol. Informasi), vol. 10, no. 2, p. 16, 2019, doi: 10.46964/justti.v10i2.105.

[3] "Mengenal Baterai Lithium-Ion 18650, Lebih Baik Dengan Power Besar," [Online]. Available: https://de-tekno.com/2018/05/mengenal-battery-18650-bettery-dengan-powerbesar/amp/.

[4] D. A. Subandi Subandi, Basuki Hari Prasetyo, "Jurnal bit," J. Bit, vol. 17, no. 2, pp. 46-52, 2020.

[5] "Kit Joule Theif Mini Inverter - Joule Theif lampu Darurat," [Online]. Available: https://studylibid.com/doc/4290780/rangkaian-joule-thief.

\section{Link publikasi OSF Project Lampu Emergency}

https://osf.io/7zej5/ 